\title{
The Dynamics of Subjective Well-Being among Recurrent Flood Victims: Development and Testing of an Integrated Model
}

\author{
Chandita Baruah ${ }^{1}$, Dilwar Hussain ${ }^{2 *}$
}

\begin{abstract}
The Indian subcontinent is vulnerable to natural disasters, predominantly devastating floods. The north-eastern region of India, especially the state of Assam, is endowed with many natural water resources, making the area highly flood-prone. However, very few studies have investigated the population's subjective well-being (SWB) in these areas despite such recurrent adversity. An integrated model of SWB is proposed and tested by combining the SWB homeostasis theory and the theory of conservation of resources. The integrated model indicated both subjective as well as objective variables as significant predictors of the SWB. A sample of 306 participants was randomly selected from two severely flood-affected areas in the state of Assam in India using a cross-sectional survey study design. Structural equation modeling was used to test two hypothesized integrated models (a direct and mediational path model). The results indicated that SWB homeostasis is maintained within the normative range of 60-65 points when measured on a 100-point continuum. Analysis of the direct path model showed that education, safe shelter, personality traits (extraversion, neuroticism, agreeableness, and openness), object and condition resources, psychological buffers (optimism and perceived control), and negative affect significantly predicted SWB. The mediational path model indicated that optimism is a significant mediator between personality traits (agreeableness, conscientiousness, and neuroticism), positive affect, resources (object resources and condition resources), and SWB. The study findings may have implications for counselling in addressing internal psychological buffers such as optimism and perceived control for maintaining the SWB of the disaster victims.
\end{abstract}

\section{Keywords}

natural disaster, floods, stressors, subjective well-being, conservation of resources theory

${ }^{1}$ Assam Don Bosco University, Guwahati, Assam, India

${ }^{2}$ Indian Institute of Technology Guwahati, Guwahati, Assam, India

*Corresponding author: dhussain@iitg.ac.in

\section{Introduction}

Climate-related changes and various human activities have led to an increase in the frequencies of natural disasters. According to the world disaster analysis (Wahlstrom \& Guha-Sapir, 2015), population density and economic/ material expansion patterns are some of the major causes of this upward trend in disaster episodes compared to climate change cyclical variations in the weather. Buildings in flood plains, earthquake zones, and other hazard-prone areas have exacerbated the likelihood of natural disasters having major catastrophic effects (Wahlstrom \& Guha-Sapir, 2015).

Amongst the most pervasive natural disasters worldwide, floods are considered the most common catastrophe worldwide, accounting for approximately $40 \%$ of all-natural disasters (Brende, 1998; Kalayjian, 1995; Wahlstrom \& GuhaSapir, 2015). The worldwide flood statistics reveal that floods account for $26 \%$ of disaster-related deaths (Brende, 1998;
Kalayjian, 1995). According to the Emergency Events Database (EM-DAT) of the Centre for Research on the Epidemiology of Disasters (CRED), Approximately $43 \%$ of all major incidents of flooding occurred between 1994 and 2013 and affected approximately 2.5 billion people worldwide (Wahlstrom \& Guha-Sapir, 2015). According to EM-DAT, India stands fifth among the 10 most-affected countries on the list of the number of people affected due to disasters (Guha-Sapir, Hoyois, \& Below, 2013).

Heavy rainfall and floods can be detrimental to human life and social developments as they may damage properties and cause deaths (Kandilioti \& Makropoulos, 2012). Heavy rainfall causes water levels to rise and riverbanks to overflow, eventually reaching flood stages. This can occur gradually or more rapidly if there is snowmelt, torrential, or continuous rain (Brende, 1998; Doocy, Daniels, Murray, \& Kirsch, 2013). The abundance of natural water resources in the Indian sub-continent makes the region susceptible to devastating flood-related disasters almost every year. According to Weibe (2006), one-third of the country's total run-off water is gen- 
erated by the north-eastern region alone, by the Brahmaputra and the Barak river systems' catchments, which receive a substantial amount of rainfall (as cited in Sarma, 2013). The river Brahmaputra, which is considered to be the lifeline of many of the riverine communities in Assam, poses a severe flood hazard, necessitating people to acclimatize to a situation of "living with floods" (Katyaini, Barua, \& Mili, 2012; Kumar \& Walia, 2013). The river turns life-threatening during the rainy season, causing catastrophic floods, eroding its banks, and large portions of cropland, homestead, and livestock (Katyaini et al., 2012). Floods repeatedly hit the state of Assam, damaging and destroying a significant amount of the livestock, goods, houses, agricultural land, and precious lives of the riverine inhabitants.

The current research aims to study the impacts of recurrent flood events and loss of resources upon the level of subjective well-being (SWB) of recurrent flood survivors. The existing literature has focused on the devastation caused by floods, but little attention has been given to survivors' psychological impact in the aftermath of such recurrent events. The present study explores the integrated effects of SWB maintenance mechanisms and the loss-gain spirals of existing resources on victims' SWB after suffering repeated flood occurrences. An integrated model of SWB, combining the SWB homeostasis theory and the theory of conservation of resources, is proposed and tested.

\section{Subjective Well-Being}

SWB comprises an individual's appraisal of their life. These appraisals can be focal (e.g., marital contentment or job satisfaction) or broad (e.g., general life satisfaction or satisfaction with the self). Additionally, these assessments can be cognitive (i.e., satisfaction judgments) or affective (i.e., moods and emotions) responses to one's individual life experiences (Cook, 2003; Ryan \& Deci, 2001). SWB is generally measured in three major components; the presence of positive affect, absence of negative affect, and life satisfaction (Ryan $\&$ Deci, 2001). The two affective factors of SWB, positive and negative affect, may independently contribute unique variance to SWB. It is unnecessary that an individual experiencing low positive affect also experiences high negative affect and vice versa. However, people with positive SWB usually have high levels of positive affect and low levels of negative affect (Franklin, 2013). SWB includes an encircling domain of a wide array of constructs that express an individual's subjective appraisal of their quality of life (Lucas, 2008; Ryan \& Deci, 2001).

\section{Subjective Well-Being Homeostatic Theory}

Research indicated that an individual's experience of SWB is controlled within a setpoint or limitation (Cummins, 1995; Morrison, 2019; Veenhoven, 1994). Literature focusing on the level of SWB found that it generally does not fit a normal curve but persistently negatively skewed (Cummins, 1995). The consistent negative skew associated with SWB has led to the argument that SWB levels are governed and regulated by a mechanism called "SWB homeostasis,"; maintaining the satisfaction level within the positive range (Cummins, 1995, 1998; Cummins, Gullone, \& Lau, 2002).

Headey and Wearing (1989) first proposed the presence of a probable "setpoint" of SWB. They suggested that, under regular conditions, SWB levels are retained within a confined range. Research on western populations resulted in developing a standard range for SWB; $75.0 \pm 2.5 \%$ Scale Maximum (SM) (Cummins, 1995). A subsequent review of western and nonwestern population means found a life satisfaction value of $70 \pm 5 \%$ SM (Cummins, 1998). The two standard deviations explain a normal distribution around a mean of $75 \% \mathrm{SM}$, which portrays the normal range of $50-100 \%$ SM within a general population sample (Cummins, 2000). However, more recent findings suggest an extension of this range to $60-90 \%$ SM, within large normative samples with the stable mean point of 75\% SM (Ayers, 2011; Cummins, 2012).

According to the SWB homeostasis theory, each individual's SWB setpoint represents their optimal level of SWB. When external circumstances cause to SWB fluctuate above or below this level, the individual uses adaptation in an attempt to maintain the setpoint (Cook, 2003; Cummins, 1995). A set of cognitive buffers may facilitate this adaptation and restore SWB to a normal range (Cummins, 2019; Cummins et al., 2002). A model proposed by Cummins et al. (2002) proposes personality, affect, and positive cognitive biases as possible regulating mechanisms of SWB and adaptation. Furthermore, prolonged and severe negative events may lead to homeostasis breakdown by negatively influencing the internal or cognitive buffers. Cognitive buffers include control, self-esteem, and optimism. Thus, according to the SWB homeostasis theory, an individual's SWB setpoint is determined by personality factors and psychological factors of the first order determinants (neuroticism and extraversion, and positive and negative affect) considerably stable. Positive cognitive biases are second-order determinants (control, self-esteem, and optimism) which comprise a regulatory system that "buffers" the psychological impact of external events by reducing the level of stress and restoring equilibrium or homeostasis to the system, thus reestablishing the SWB setpoint level (Cook, 2003; Cummins, 2019; Cummins \& Nistico, 2002; Morrison, 2019).

Stress associated with recurrent aversive life conditions, such as poverty, poor housing or low-quality shelter, insufficient fulfillment of basic needs, economic uncertainty, recurrent aversive conditions of life, or disasters, is often considered to be a significant predictor of SWB homeostatic breakdown (Cook, 2003; Mahmood \& Ghaffar, 2014). This study explores the SWB of recurrent flood victims in the context of the homeostatic theory. It is possible that natural disasters, such as recurrent floods, may have an adverse effect on the homeostatic mechanism of SWB. It would be crucial to identify how the first and second-order determinants influence the level of SWB and homeostasis. 


\section{Figure 1}

A Homeostatic Model for Subjective Wellbeing (adapted from Cummins et al., 2002)

FIRST ORDER DETERMINANTS

AS

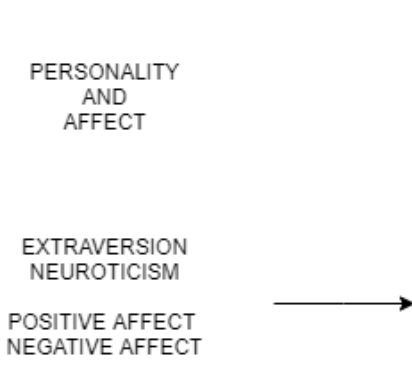

SECOND ORDER DETERMINANTS

AS

INTERNAL BUFFERS

(POSITIVE INPUT)

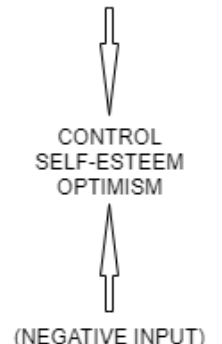

OUTPUT

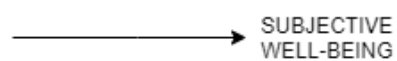

\section{Conservation of Resources Theory}

The Conservation of Resources (COR) theory can be considered an integrative stress theory that considers both environmental and internal processes in defining stress (Hobfoll, 1989, 2001). The basic precept of COR theory (Hobfoll, 1989, 2001) states that every individual has an intrinsic, as well as a learned drive to create, foster, conserve, and protect the quality and quantity of their resources. The COR theory's fundamental concept states that an individual utilizes internal and external resources to strengthen their ability to cope with stressors. Therefore, the continuous loss of resources may lead to the breakdown of coping mechanisms, causing psychological distress. COR theory considers both environmental and internal processes equally important in promoting well-being and prevention of stress (Hobfoll, 1989, 2001; Lightfoot, Lesen, \& Ferreira, 2020). According to the COR theory, "stress occurs when people's psychological or material resources are threatened with loss, are actually lost, or when individuals must invest resources without obtaining reasonable resource gain" (Hall et al., 2008, p. 23). It defines stress as a result of the environment where there is a perceived threat of net loss of resources, the actual loss of resources, or a perception that an investment of resources is not producing or adding to the net gain (Cook, 2003; Hobfoll \& Stephens, 1990; Merino, Privado, \& Arnaiz, 2019).

The COR theory proposes four kinds of resources whose loss or gain may lead to an individual's distress or well-being. Object resources include material possessions, which augment the objective quality of life. Energy resources include money, credit, owed favors, and knowledge, which are considered significant objective predictors to enhance the quality of life. Condition resources relate to valued and sought-after conditions that involve relationships and status, such as; being married, having a family, and work seniority. Personal characteristics resources include internal, psychologically-based aspects, such as personal traits and skills, that promote stress resistance (Cook, 2003; Hobfoll, 1989; Merino et al., 2019).
COR theory can help provide insights into the role of internal and external resources in coping with stressors and how the resource loss spirals can contribute to the breakdown of coping mechanisms. Therefore, this theory is used to identify the dynamics of SWB in the context of recurrent flood victims.

\section{Integration of SWB Homeostasis Theory and COR Theory}

In the present study, two theories, the theory of SWB homeostasis (Cummins et al., 2002) and the COR theory (Hobfoll, 1988), were integrated to understand the dynamics of SWB among recurrent flood victims. Although the COR theory and the theory of SWB homeostasis each emerged from a different set of literature, stress, and quality of life, respectively, they share a common origin of framework and values. The basic concept of the COR theory states that an individual's internal and external resources are utilized to maintain the ability to cope with stressors, where continuous resource loss spirals lead to the breakdown of coping mechanisms, causing psychological stress (Hobfoll, 1989, 2001; Lightfoot et al., 2020). COR theory considers both environmental and internal processes equally important in promoting well-being and prevention of stress (Hobfoll, 1989, 1988). Likewise, SWB homeostasis theory elucidates the psychological determinants that act as buffers against external stressors to protect homeostatic failure and maintain the level of SWB within the setpoint range (Cook, 2003; Cummins et al., 2002). Cummins (2010) proposed that SWB homeostatic mechanisms are composed of two different kinds of buffers; internal and external. The cognitive buffers are referred to as the internal buffers, whereas wealth and personal relationships are considered the most powerful external buffers of SWB homeostasis (Cummins, 2010; Tiliouine, Cummins, \& Davern, 2006).

\section{The Present Study}

Both COR and SWB homeostasis theory share common as well as unique factors that can influence well-being. There- 
fore, this study attempted to test an integrated model by combining factors from both COR and SWB homeostasis theory. The COR theory included various resource categories that are necessary for coping and well-being. Object and energy resources are found to be the significant objective predictors of quality of life (Cummins, 2010). The SWB homeostasis model does not include these factors despite the growing evidence favoring them as influencing SWB (Cook, 2003). The condition resources of COR theory relate to valued and soughtafter conditions of human life, which involves relationships and status (Cook, 2003; Hobfoll, 1989). Furthermore, a consistent body of literature has shown that condition resources such as perceived social support are a significant predictor of SWB with a positive correlation between social support and SWB (Cook, 2003; Cummins, 2010). This factor is also not conceptualized within the SWB homeostasis model. Also, personal characteristics resources of the COR theory may include some cognitive buffers of SWB homeostasis theory such as self-esteem and control (Cook, 2003). Personal characteristics resources generally promote stress resistance (Hobfoll, 1988). In addition to optimism, self-esteem and control collectively comprise the cognitive buffers, representing the second-order determinants of the SWB homeostasis theory (Cook, 2003; Scheier \& Carver, 1992). Additionally, stable individual personality dispositions and affect are not incorporated in the COR model, as the framework is based upon a simple conceptualization of the relationship between resources and stress (Cook, 2003). However, the influences of these individual difference factors on stress quite significant and cannot be overlooked (Cook, 2003). These stable dispositional factors of personality and affect may play a major role in identifying other less stable factors, such as optimism, control, and selfesteem (Cook, 2003; Cummins et al., 2002). These factors may, in turn, influence the way the stressors are perceived, the way coping techniques are used to deal with stressors, and the predisposition to stressful or aversive life events Cook (2003). Therefore, an integrated model combining both SWB homeostasis and COR theory is conceptualized and tested in this study. The description of the model is below (see Figure 2).

The hypothesized integrated model's first-order determinants include personality and affect, which are considered predisposing factors and quite stable in nature. The secondorder determinants are the cognitive buffers mentioned in the SWB theory; self-esteem, control, and optimism. This category of determinants subsequently overlaps with the personal characteristics resources; therefore, in the model, personal characteristics resources are submerged in the second-order determinants, without considering it as a separate resource category. The third category of determinants includes the three remaining categories: condition, energy, and object resources. Environmental stressors are included in the model as they are considered an influential factor affecting cognitive buffers and can also influence the level of SWB directly during extreme events. Therefore, the scheme of variables included in the hypothesized integrated model proposes that personality, affect, resource categories (condition, energy, and object resources), and environmental stressors will influence cognitive buffers (self-esteem, control, and optimism), which in turn will determine SWB of an individual.

\section{Research Questions}

Based on the above-mentioned integrated model, the following specific research questions were explored in this study:

1. What is the goodness of fit of the hypothesized integrated model proposed by combining both SWB homeostasis and COR theory?

2. What is the level of SWB among the recurrent flood victims? Do these recurrent flood survivors maintain the level of SWB within its normative range?

3. What are the roles of environmental stressors, personality traits, affect, cognitive buffers, and resources (object, condition and energy) on SWB among the recurrent flood survivors?

4. Do internal psychological buffers (self-esteem, perceived control, and optimism) act as a mediator between predictor variables (flood related environmental stressors, personality and affect and the three categories of resources) and outcome variable (subjective wellbeing)?

\section{Method}

\section{Sample}

This study included a sample of severely flood-affected areas of Assam (a north-eastern state of India). The participants were randomly selected from two distinct areas of Assam; the Majuli Island district (the largest river island in the Brahmaputra river) and the Jia Dhal and Gai River areas of the Dhemaji district. The relevant flood control departments were approached to seek permission and collect information about the affected individuals and families in these areas. Furthermore, a list of individuals and families adversely impacted by the flood was prepared. Finally, the participants were randomly selected from the list using a computerized random number list. The total number of participants was 306, out of which 154 participants were from Majuli Island and 152 participants were from Dhemaji District. There were 179 female $(58.5 \%)$ and 127 male $(41.5 \%)$ respondents participating in the survey interview. The age range of the participants was $18-86$ years $(M=38.45, S D=13.59)$. Out of 306 participants, $13.4 \%$ never went to school, $6.9 \%$ attended elementary school, $44.8 \%$ attended high school, $18 \%$ had completed senior secondary school, $2.9 \%$ were college dropouts, $12.1 \%$ were college graduates, and $2 \%$ were postgraduates. The monthly income of the majority of the sample (66\%) was in the range of 13 to 132 US\$, and the remaining $34 \%$ had 


\section{Figure 2}

Hypothesized Integrated Model

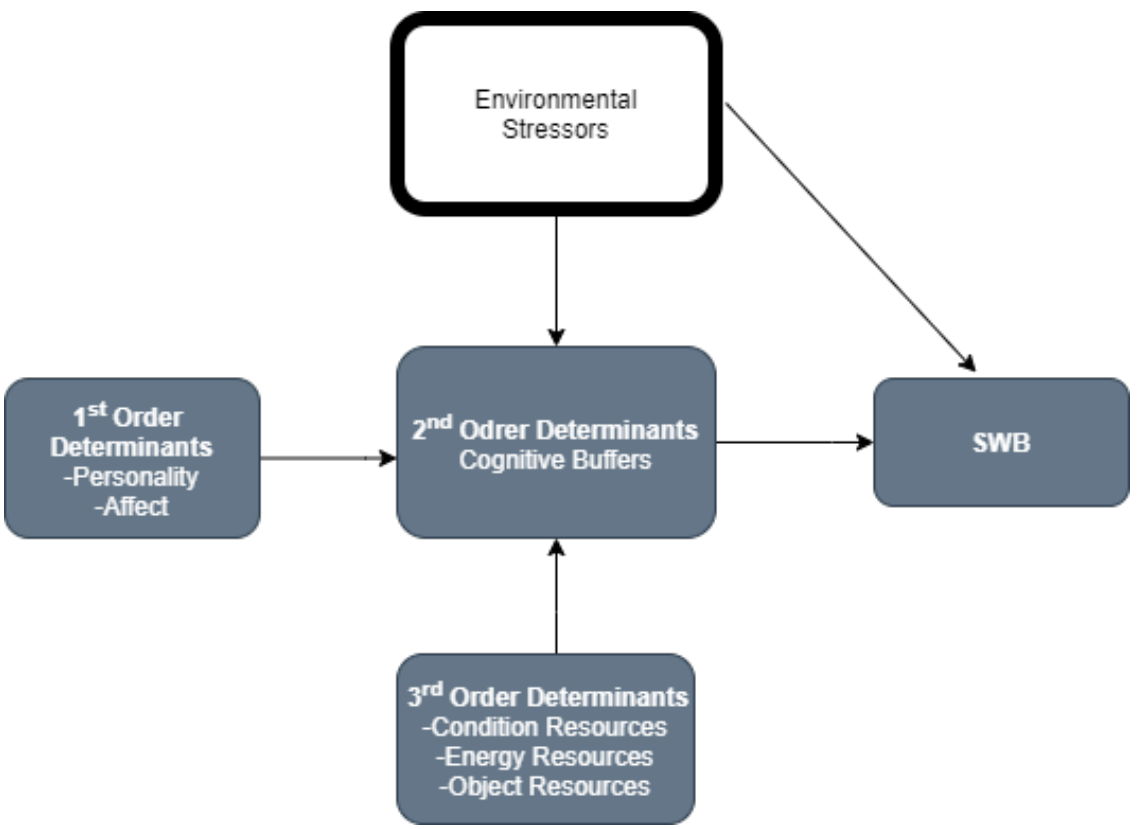

Table 1

Age Distribution of Participants

\begin{tabular}{lllllll}
\hline $\boldsymbol{N}$ & Range & Min. & Max. & $\boldsymbol{M}$ & $\boldsymbol{S D}$ & Var. \\
\hline 306 & 68 & 18 & 86 & 38.45 & 13.59 & 184.57 \\
\hline
\end{tabular}

Table 2

a monthly income above 132 US\$. Therefore, most of the participants were in the low-income category. Demographic information is shown in Tables 1 and 2.

\section{Measures}

The assessment tools used for data collection are described below.

\section{Personal Wellbeing Index (PWI)}

The Personal Wellbeing Index (PWI) scale is a comprehensive measure of Quality of Life (QoL). The scale comprises seven domains of personal well-being; standard of living, health, achievements in life, personal relationships, safety, community connectedness and future security. The domains correspond to the domains of QoL. The Cronbach's alpha of the scale lies between .70 and .85 for the Australian population as well as other western countries (Lau, Cummins, $\&$ Mcpherson, 2005). The participants rated their level of satisfaction on an 11-point Likert scale, ranging from $0=n o$ satisfaction at all, to $10=$ completely satisfied (Cook, 2003;

Descriptive Statistics of the Demographic Variables

\begin{tabular}{lll}
\hline Demographic Variable & Frequency & Percent \\
\hline Gender & & \\
Male & 127 & 41.5 \\
Female & 179 & 58.5 \\
Education & & \\
Never went to school & 41 & 13.4 \\
Elementary Education & 21 & 6.9 \\
High School & 137 & 44.8 \\
Senior Secondary School & 55 & 18 \\
Some College Education & 9 & 2.9 \\
College Graduate & 37 & 12.1 \\
Master Degree \& above & 6 & 2 \\
Income & 202 & 66 \\
13 to 132 US $\$$ & 104 & 34 \\
Above 132 US\$ & & \\
Study areas & & \\
Majuli & 154 & 50.3 \\
Dhemaji & 152 & 49.7 \\
\hline
\end{tabular}

\section{Big Five Inventory-10 (BFI-10)}

The BFI-10 is a short version of the Big Five Inventory 44 (BFI-44) personality measure, developed by Rammstedt 
Table 3

Frequency of Flood Related Stressors

\begin{tabular}{lc}
\hline Flood related stressors & Sample percentages \\
\hline Lack of safe shelter & 56.2 \\
Property damage & 99.7 \\
Negative effect on work & 97.7 \\
Endangerment Situation & 92.2 \\
Evacuation from Home & 40.8 \\
Death of loved ones & 6.00 \\
Loss of Livestock & 71.6 \\
\hline
\end{tabular}

and John (2007). The BFI-10 defines 2 items for each of the Big Five Dimensions of personality; extraversion, agreeableness, conscientiousness, neuroticism and openness. The test-retest reliability (.75) and convergent validity (.67) scores indicate that the scale retained average psychometric properties. The participants rated their feelings on a 5-point Likert scale, ranging from $1=$ disagree strongly to $5=$ agree strongly (Rammstedt \& John, 2007).

\section{The Positive and Negative Affect Schedule (PANAS)}

The Positive and Negative Affect Schedule (PANAS), developed by (Watson, Clark, \& Tellegen, 1988), is a selfreport measure that consists of 20 items indicating positive and negative affect (as cited in Crawford \& Henry, 2004). The Cronbach Alpha scores indicate good internal consistency of the measure (Cronbach's alpha $=.89$ for positive affect and .85 for negative affect) The interviewers rated their feelings on a 5-point Likert scale, ranging from $1=$ very slightly or not at all to $5=$ extremely (Crawford \& Henry, 2004; Watson et al., 1988).

\section{Rosenberg Self-Esteem Scale}

The Rosenberg Self-Esteem Scale (Rosenberg, 1965) is a 10-item self-report instrument measuring global self-worth. The scale measures both positive and negative feelings about the self and a higher score represents a higher level of selfesteem (Rosenberg, 1965). The items are answered using a 4-point Likert scale, ranging from $1=$ strongly agree to $4=$ strongly disagree. The scale is widely used because of its adequate internal consistency (Cronbach's alpha $=.77$ and $.88)$ and high test-retest reliability $(r=.82)$ (Cook, 2003; Rosenberg, 1965).

\section{Perceived Control of Internal States Scale (PCOISS) Life Orientation Test-Revised (LOT-R)}

The Life Orientation Test-Revised (LOT-R) measures the extent of individual's favourable expectations or optimistic outlook on life (Scheier and Carver, 1985; as cited in Cook, 2003). The scale has 10 items with 5-point Likert rating scale ranging from $0=$ strongly disagree to $4=$ strongly agree . High scores indicate high levels of optimism. The LOT-R has high internal consistency with a Cronbach's alpha of .82 (Scheier, Carver, \& Bridges, 1994).

\section{Cumulative Exposure Indicator (CEl1)}

The Cumulative Exposure Indicator 1 (Verger et al., 2003) is a measure that evaluates an individual's cumulative stress after experiencing a natural disaster. CEI1 identifies seven categories of stressors during the exposure to flood; physical presence, property damage, effect on work, endangerment situations, assistance during the flood, evacuation from home, and loss of pets. The items are presented in "yes" and "no" $(1=y e s ; 0=n o)$ dichotomous fashion. The total score combining all items can range from 0 to 11 . Approximately the scores below 4 indicates low levels of stressful experience; scores between 4 to 6 indicates moderate levels of stressful experience and a score of 7 and above indicates high levels of stressful experience.

\section{Resources Questionnaire}

The Resources Questionnaire was developed from The Conservation of Resources Evaluation (COR-E). The original version of COR-E was developed by Hobfoll and Lilly (1993), which has a list of 74 resources that people respond to in terms of their degree of loss or gain, on a 5-point Likert-type rating scale ranging from $0=$ not at all, or not applicable, to $4=$ to $a$ great degree. On the basis of literature review, characteristics of the present study and sample, 14 items were carefully selected from the original version of COR-E. This 14-items measure included five items for each of the object and energy resource categories, and four items for the condition resource category, each rated using the same Likert scale.

\section{Procedure}

Ethical approval for the study was given by the Doctoral Review Committee of the Institution. Informed consent was also obtained from the appropriate authority personnel and participants. Confidentiality about the identity of the participants has been maintained throughout the study. The questionnaire was translated from English to Assamese and Missing (the participants' vernacular languages). This was followed by a back-translation method, carried out by independent bilingual translators, who were blind to the original English version of the questionnaires. Every participant was visited personally, and the interview was started with a general conversation in order to make the participant feel at ease. A rapport was built with the participants before the data collection. A rapport was established with the participants by spending some time in mutual informal conversation. The questionnaire was administered to the illiterate participants $(n=41)$ by an interviewer. The participants were read the questionnaire in their vernacular language exactly as per the questionnaire without changing the meaning/adding additional information to the questions in order to control the response bias. Most of the interviews took place at the participants' home or work premises, depending on what was most convenient for each participant. A pilot study was conducted on 33 samples to ensure the suitability and validity of the present study's measures. Each questionnaire took approximately 30-45 minutes to complete. 
Table 4

Reliability, Validity and CFA of the Scales

\begin{tabular}{|c|c|c|c|c|c|c|c|c|c|c|c|c|}
\hline \multirow[t]{2}{*}{ Variables } & \multicolumn{12}{|c|}{ No. of Items } \\
\hline & Orig. & Retain. & $\alpha$ & CR & AVE & MSV & $\mathbf{x}^{2} / \mathbf{d f}$ & GFI & CFI & NFI & RMSEA & $\begin{array}{l}\text { Factor } \\
\text { Loadings }\end{array}$ \\
\hline COR-E & 14 & 13 & - & - & - & - & 2.92 & 0.9 & 0.95 & 0.93 & 0.07 & .33 to .84 \\
\hline Object Resources & 5 & 5 & 0.77 & 0.78 & 0.76 & 0.65 & - & - & - & - & - & - \\
\hline Condition Resources & 4 & 3 & 0.73 & 0.76 & 0.56 & 0.42 & - & - & - & - & - & - \\
\hline Energy Resources & 5 & 5 & 0.85 & 0.86 & 0.77 & 0.65 & - & - & - & - & - & - \\
\hline PANAS & 20 & 17 & - & - & - & 0.08 & 1.61 & 0.90 & 0.96 & 0.91 & 0.04 & .30 to .91 \\
\hline Positive Affect & 10 & 9 & 0.84 & 0.84 & 0.79 & - & 1.93 & 1.00 & 0.98 & 0.95 & 0.05 & .30 to .74 \\
\hline Negative Affect & 10 & 8 & 0.79 & 0.75 & 0.72 & - & 0.20 & 1.00 & 0.98 & 0.97 & 0.05 & .30 to .92 \\
\hline BFI-10 & 11 & 10 & - & - & - & - & 2.11 & 1.00 & 0.97 & 0.95 & 0.07 & .36 to .76 \\
\hline Extraversion & 2 & 2 & 0.76 & 0.78 & 0.77 & 0.69 & - & - & - & - & - & - \\
\hline Openness & 2 & 2 & 0.85 & 0.86 & 0.81 & 0.58 & - & - & - & - & - & - \\
\hline Agreeableness & 3 & 2 & 0.76 & 0.79 & 0.78 & 0.40 & - & - & - & - & - & - \\
\hline Conscientiousness & 2 & 2 & 0.74 & 0.78 & 0.76 & 0.68 & - & - & - & - & - & - \\
\hline Neuroticism & 2 & 2 & 0.78 & 0.77 & 0.87 & 0.56 & - & - & - & - & - & - \\
\hline Self-Esteem & 10 & 10 & 0.86 & 0.87 & 0.6 & - & 2.53 & 0.90 & 0.95 & 0.91 & 0.07 & .47 to .72 \\
\hline Optimism & 10 & 10 & 0.78 & 0.81 & 0.65 & - & 2.88 & 0.94 & 0.92 & 0.89 & 0.07 & .32 to .76 \\
\hline Psychological Control & 18 & 16 & 0.92 & 0.92 & 0.76 & - & 2.65 & 0.9 & 0.95 & 0.92 & 0.07 & .30 to .87 \\
\hline Subjective Wellbeing & 8 & 8 & 0.74 & 0.74 & 0.28 & - & 1.35 & 1.00 & 0.97 & 0.93 & 0.05 & .32 to .75 \\
\hline
\end{tabular}

Note: $\alpha=$ cronbach's alpha; $\mathrm{CR}=$ composite reliability, $\mathrm{AVE}=$ average variance extracted, $\mathrm{MSV}=$ maximum shared variance, $\mathrm{GFI}=$ goodness-of-fit index; CFI = comparative fit index; NFI = normed fit index; $x^{2} / \mathrm{df}=$ chi square/degrees of freedom; RMSEA = root mean square error of approximation.

\section{Results}

\section{SWB Scores}

The mean scores of SWB (PWI) $(M=62.40, S D=12.11)$ and Global Life Satisfaction (GLS) $(M=64.28, S D=20.38)$ indicate that SWB homeostasis is maintained within the normative range of $60-90$ points on a 100 -point continuum for non-western sample. However, the score falls at the lower end of the continuum and below the western norm (70-90\% SM). The results also indicate a significant existence of gender difference $t(304)=1.97, p<0.05$ in the scores of SWB. Male participants $(M=63.94, S D=12.55)$ reported higher SWB as compared to the female participants $(M=61.30, S D=11.70)$.

\section{Flood Related Stressors}

The results of the study indicated that participants experienced various flood related stressors. Percentages of participants who have experienced these stressors are shown in Table 3. It is clear that participants have experienced almost all major types of flood related stressors. Highest percentage of participants reported property damage, negative effect on occupational work, exposure to endangered situations, and loss of livestock.

\section{Reliability, Validity, and CFA}

Structural Equation Modeling (SEM) was used to test the hypothesized integrated model. SPSS Amos 22.0 was used to analyze the data. Along with the descriptive statistics and the standard regression weights/factor loadings, the model fit indices of the goodness-of-fit index (GFI), comparative fit index (CFI), normed fit index (NFI), and root mean square error of approximation (RMSEA) of each scale, used in the present study, were obtained. The items with loadings below .30 were eliminated (Singh, Suar, \& Leiter, 2012). This step is necessary to identify and eliminate, if necessary, the items that had extremely poor loadings/weights and to reiterate the convergent validity of the items within each construct (Singh et al., 2012). The entire model fit indices of GFI, CFI, and NFI were above the recommended limit of .90, suggesting a good fit of the items to its constructs (Khine, 2013). RMSEA is also below .07 for all the constructs (Khine, 2013). The Cronbach's alphas of all the items were greater than .60, which again suggests a good internal consistency of the items in each construct (Nunnally, 1967). The convergent and discriminant validity of the constructs were tested using confirmatory factor analysis (Singh et al., 2012). The composite reliability (CR) value for all the constructs was above the recommended range of .70 (Khine, 2013). The average variance extracted (AVE) of all the scales were well above .50 (Khine, 2013). The maximum shared squared variance (MSV) for COR, PANAS, and BFI-10 were less than their concurrent AVE values, ensuring the discriminant validity of the constructs (Khine, 2013). Table 4 shows a detailed description of all the constructs' CFA, 
Table 5

Path Coefficients (Regression Weights) of the Predictors with $S W B$

\begin{tabular}{lccc}
\hline Predictors & $\beta$ & S.E. & C.R. \\
\hline Object Resources & $0.209^{* *}$ & 0.214 & 4.079 \\
Condition Resources & $0.10^{*}$ & 0.219 & 1.865 \\
Education & $-0.143^{* *}$ & 0.377 & -2.97 \\
Neuroticism & $-0.117^{*}$ & 0.403 & -1.802 \\
Agreeableness & $0.169^{* *}$ & 0.365 & 3.514 \\
Extraversion & $0.134^{* *}$ & 0.382 & 2.261 \\
Control & $0.141^{*}$ & 0.094 & 1.982 \\
Openness & $0.131^{*}$ & 0.49 & 2.238 \\
Negative Affect & $-0.141^{* *}$ & 0.173 & -2.386 \\
Optimism & $0.268^{* *}$ & 0.156 & 4.76 \\
Safe Shelter & $0.14^{* *}$ & 1.197 & 2.725 \\
\hline
\end{tabular}

Note: Dependent variable is SWB; S.E. = Standard error; CR $=$ Critical ratio; $* p<.05, * * p<.01$

reliability, and validity scores.

\section{Path Analysis: Direct Path Model}

A direct path model was tested with all the predictor variables and the control variables to evaluate the direct effect of the predictor variables on the outcome variable. The structural equation modeling using SPSS Amos with maximum likelihood method was carried out to analyze the predictors of SWB in the present study. The demographic variables of age, education, income were entered into the model. All the other predictor variables of personality (BFI dimensions) affect (positive negative affect), cognitive buffers (self-esteem, perceived control, and optimism), resource categories (object, condition, and energy), and environmental stressors (safe Shelter, property damage, death of loved ones and loss of livestock) were entered, with subjective well-being as the dependent variable. The results showed that among the sociodemographic variables, only education is found to be a significant predictor of SWB with a negative direction of association. Among the other independent variables, three of the Big Five dimensions of personality (extraversion, agreeableness, and openness), object and condition resources, optimism, perceived control, and safe shelter were found to be significant positive predictors of SWB. Furthermore, neuroticism and negative affect were found to be significant negative predictors of SWB. The results are shown in Tables 5 and 6.

\section{Goodness of Fit and Path Analysis of the Hypothe- sized Integrated Model}

The integrated hypothesized model was run in SPSS Amos using the maximum likelihood method. This model included environmental stressors, personality traits, affect, and resources as independent variables, psychological buffers (op- timism, control, and self-esteem) as mediators, and SWB as the dependent variable. Based on the SEM results, a reduced model was obtained. Self-esteem and perceived psychological control did not predict the dependent variable (SWB) and, hence, were deleted from the model. However, optimism ( $\beta$ $=0.45, p<.001)$ had a significant path with SWB. Therefore, the reduced model included only optimism as the mediator. Among the independent variables, the reduced model included three personality variables (agreeableness, conscientiousness, and neuroticism), positive affect, and two resource variables (object resources and condition resources). It was found that agreeableness $(\beta=0.12 ; p<.01)$, conscientiousness $(\beta=$ $0.14 ; p<.01)$, positive affect $(\beta=0.45 ; p<.01)$, object resources $(\beta=0.15 ; p<.01)$ and condition resources $(\beta=$ $0.10 ; p<.01)$ were significant positive predictors of optimism; whereas, neuroticism $(\beta=-0.21 ; p<.01)$ was found to a significant negative predictor of optimism. The results are shown in Tables 7 and 8.

The revised model showed better fitness with the data, as indicated by the fit indices. The path coefficients are equivalently represented by the multiple regression analysis (Singh et al., 2012). The model fit measures of all the models indicated that the chi-squares $\left(x^{2}\right)$ of these models are highly significant $(p<.001)$. However, for the similarity between the observed and model-implied covariance matrix, a non-significant chisquare is desired. As the chi-square is highly sensitive to sample size, a relative chi-square $\left(x^{2} / \mathrm{df}\right)$ was considered to reduce its sensitivity. Ideally, to maintain the model parsimony, $x^{2} / \mathrm{df}$ value should not exceed 3.0 Kline (1998); Singh et al. (2012); Tomyn and Cummins (2011). Although the values for the full models are a little higher, the estimated relative chi-square values for the revised models are well within the recommended criteria of .30 (Kline, 1998).

\section{Sobel Test}

To check the significance of the mediational paths, a Sobel test was conducted using the Sobel calculator (Preacher $\&$ Leonardelli, 2003). A mediation analysis was carried out to check the mediation effect of the cognitive buffer (optimism) between the independent variables of the reduced model and the dependent variable (SWB). The Sobel test results (Table 9) showed that optimism is a significant mediator between agreeableness, conscientiousness, neuroticism, positive affect, object resources, condition resources, and SWB.

\section{Discussion}

This study attempted to investigate the psychological dimensions of recurrent flood survivors in one of India's most severely flood-affected states. The significance of this study lies in its attempt to study an understudied population. Despite the high frequency and severity of natural disasters, particularly floods in Assam, an almost negligible amount of academic research addresses the psychological dimensions of recurrent flood victims. This study is an attempt to address this gap in research. 
Table 6

Fit Indices of the Direct Path Model

\begin{tabular}{lcccccc}
\hline Models & $x^{2} / \mathbf{d f}$ & P & GFI & CFI & NFI & RMSEA \\
\hline Full Model & 4.41 & 0.001 & 0.78 & 0.68 & 0.73 & 0.11 \\
Reduced Model & 2.80 & 0.001 & 0.95 & 0.93 & 0.90 & 0.07 \\
\hline
\end{tabular}

Note $:$ GFI = goodness-of-fit index CFI = comparative fit index NFI $=$ normed fit index; $x^{2} / \mathrm{df}=$ chi square $/$ degrees of freedom; RMSEA $=$ root mean square error of approximation; $\mathrm{P}=$ Probability .

Table 7

Standardized Beta Coefficients of the Reduced Meditational Model

\begin{tabular}{llcccc}
\hline Dependent Variables & & Predictors & Standardized Beta Coefficients & SE & CR \\
\hline Optimism & $\leftarrow$ & Agreeableness & $0.12^{* *}$ & 0.117 & 2.643 \\
Optimism & $\leftarrow$ & Conscientiousness & $0.14^{* *}$ & 0.115 & 2.834 \\
Optimism & $\leftarrow$ & Neuroticism & $-0.21^{* *}$ & 0.107 & -4.231 \\
Optimism & $\leftarrow$ & Positive Affect & $0.45^{* *}$ & 0.042 & 9.082 \\
Optimism & $\leftarrow$ & Object Resources & $0.15^{* *}$ & 0.065 & 3.370 \\
Optimism & $\leftarrow$ & Condition Resources & $0.10^{* *}$ & 0.065 & 2.287 \\
PWI (SWB) & $\leftarrow$ & Optimism & $0.45^{* *}$ & 1.353 & 8.682 \\
\hline
\end{tabular}

Note. $\mathrm{SE}=$ Standard error; $\mathrm{CR}=$ Critical ratio; ${ }^{*} p<.05, * * p<.01$

This study focused on the maintenance of the level of SWB homeostasis of the recurrent flood survivors of Assam during and post-flood conditions. Two theories, that is, SWB homeostasis theory and conservation of resources theory (COR theory), are explicitly integrated to increase the illustrative power of factors influencing SWB among the recurrent flood survivors. According to the hypothesized model, under the conditions of chronic/severe distress, both internal and external resources, help ward off the negative feelings, thereby maintaining the homeostatic equilibrium.

It is clear that participants have experienced almost all major types of flood-related stressors. The highest percentage of participants reported property damage, negative effects on occupational work, exposure to endangered situations, and loss of livestock. Many participants also reported a lack of safe shelter, loss of loved ones, and evacuation from their homes as major stressors during the floods. Participants of the present study have repeatedly been experiencing these losses and stressors almost every year and, sometimes, more than once in a year. Such stressors may have a cumulative effect and long-term repercussions for their physical and mental health.

The SWB Homeostasis theory states that every person has a genetic setpoint for SWB that lies within a narrow range of $70-80 \%$ SM on a standard 0-100 point scale continuum (Cummins et al., 2002). The average consistency of the findings for the set point of SWB is 75\% SM with 70-80\% SM as the normal range in western cultures (Cummins, 2019; Cum- mins et al., 2002; Lai, Cummins, \& Lau, 2013; Tiliouine et al., 2006). However, the recent literature of SWB suggests a distribution of $70-90 \%$ SM with an average score of $80 \%$ SM to be the positive (above neutral) levels of well-being of population distribution for western cultures (Chen \& Davey, 2008; Cummins \& Wooden, 2014). This norm falls slightly at a lower range for the non-western populations, inferring a range of 60-70\% SM (Chen \& Davey, 2008; Cummins, 2019; Tiliouine et al., 2006).

The present study results indicated a SWB score of 62.40 and a Global Life Satisfaction (GLS) score of 64.28 for the recurrent flood victims. Both scores fall under the range of 60 $70 \%$ SM suggested by Cummins (1998). The mean score of SWB indicates that the SWB score is falling below the global set point for a western sample, which is $70-90 \%$ SM but falling at the lower end of the setpoint range for non-western samples (60-70\% SM). The results confirm previous studies conducted in non-western cultures such as China, Singapore, Taiwan, and Macau (Chen \& Davey, 2008). The results indicated a lower level of SWB in the empirical measurement of satisfaction of life in non-western cultures. Current findings also support the basic precept of the SWB Homeostatic theory, according to which an individual's level of SWB is maintained within a narrow positive range by a set of psychological processes (Chen \& Davey, 2008; Tiliouine et al., 2006). This result also reflects that the present sample is highly vulnerable to SWB homeostasis breakdown. SWB homeostatic defeat may occur under the conditions of prolonged or recurrent stress or 
adverse factors (recurrent floods in the present sample). However, such homeostatic defeat is usually regulated through the process of adaptation, whereby cognitive buffers restore SWB levels to the normal range (Cummins et al., 2002). Therefore, as the present sample is highly vulnerable to homeostatic defeat, cognitive buffers (optimism, control, and self-esteem) may work overtime to maintain the homeostasis.

The present study results indicated a significant existence of gender difference in experiencing SWB. Males scored higher than females in SWB. The literature shows mixed findings in gender and SWB, with some studies showing gender differences (Mahmood \& Ghaffar, 2014) while others no difference (Tomyn, Mellor, Fuller-Tyszkiewicz, Cummins, \& Tanton, 2017). A plausible reason for this difference could be the cultural variations or the cultural response bias (Lau et al., 2005). India is predominantly a masculine society, where the traditional societies consider men as primary figures of power and authority; While women are placed in secondary positions in terms of power, status, decision-making, allocation of food, health, education, and/or earnings for their family (Hofstede, 2001; Suar \& Gochhayat, 2016). It is quite apparent in some suburb Indian societies where female participants are still less confident in independent or autonomous decision making (Nussbaum, 2000). Nussbaum (2000) stated that adaptation is the usual phenomenon in developing countries, like India, where women often get used to deprivation and constrained liberties. The low literacy rate or illiteracy among female participants could also be one of the major reasons for gender differences. According to India's government census of 2011, males' literacy rate was $82.1 \%$, and females was $65.5 \%$.

The SWB homeostasis model states that any deviation of the level of SWB from the setpoint is regulated through adaptation and habituation. Therefore, cognitive buffers are actively engaged in restoring the level of SWB to its narrow positive range (Cummins et al., 2002). Further, Cummins (2010) proposed that both internal (cognitive buffers) and external resources (wealth, personal relationship, and so forth) are equally important in the maintenance of the SWB Homeostasis. In the present study, it was hypothesized that under the conditions of recurrent stressors, both the internal and external buffers would be actively engaged in restoring and maintaining the level of SWB Homeostasis. Both direct and mediational path models of the study confirm this hypothesis.

In the direct path model, education is found to be a significant negative predictor of SWB. This finding probably reflects the situation of the sample. To a certain extent, active reciprocity of education, income, and SWB may be a plausible reason for such an inverse relationship in the present study. Similar findings were reported by Tiliouine et al. (2006) in Algeria, where they found that people with no formal educational qualification scored the highest mean on the SWB. Higher education with lower income and quality of life may lead to lower SWB.

Four of the Big-Five dimensions; extraversion, agreeableness, neuroticism, and openness, were found to be significant predictors of SWB. A large volume of literature documented that personality is the key element in the sustained stability of the SWB Homeostasis Davern, Cummins, and Stokes (2007); Gutiérrez, Jiménez, Hernández, Pcn, et al. (2005). The present findings support many past studies where neuroticism was found to be a significant predictor of SWB, along with extraversion (Cummins et al., 2002; Davern et al., 2007; Diener \& Lucas, 1999; Gutiérrez et al., 2005; Hayes \& Joseph, 2003). Studies have also documented a positive direction of association of openness and agreeableness with SWB (Henning, Hansson, Berg, Lindwall, \& Johansson, 2017; Soto, 2015). According to Cummins et al. (2002), personality is one of the strongest predictors of set point range for an individual's entire homeostatic system as it provides a stable, effective background.

The previous studies frequently documented affect as another stable significant predictor of SWB (Cummins et al., 2002). The present study results showed negative affect as a significant negative predictor of the SWB. These findings indicated that the level of SWB increases with a decreased level of negative affect. Lowered negative valence states often define the optimal state of SWB, and there are a host of studies defining the link between negative affect with anxiety/depression (Burns \& Machin, 2010; Vitters $\varnothing$, 2001). However, in the direct model, positive affect didn't show any significant relationship with SWB.

Among the three cognitive buffers, optimism and perceived control were found to be significant positive predictors of SWB. However, self-esteem failed to explain any significant variance in SWB among the present sample. The existing literature documented optimism as a strong positive predictor of SWB since people high on optimism accumulate positive expectations of the future and hold a positive outlook for life events (Cummins, 2010; He, Cao, Feng, Guan, \& Peng, 2013). Optimism enhances the perceived ability to manage the aftereffects of potentially stressful events (Cherry et al., 2017; Prati \& Pietrantoni, 2009) and, thereby, increase one's perceived control. A sense of control over their external adversities decreases the environmental and psychological stressors, which, in turn, helps maintain their homeostatic equilibrium.

Among the external resources, object and condition resources were found to be significant positive predictors of the SWB. These findings confirm previous literature suggesting wealth and personal relationships are the most powerful predictors of SWB (Cummins, 2000, 2010, 2019; Tomyn et al., 2017). A study conducted by Galinha, Garcia-Martin, Oishi, Wirtz, and Esteves (2016) found that satisfaction with relationships is a significant predictor of SWB in India. These predictors help victims to deal with the external adversities in the wake of such recurrent flood events.

The results of the hypothesized integrated model (mediational path model) indicated that optimism is a significant mediator variable between personality traits (agreeableness, conscientiousness, and neuroticism), Positive affect, Resources (object resources and condition Resources), and SWB. How- 
Table 8

Fit Indices of the Meditational Path Model

\begin{tabular}{lcccccc}
\hline Models & $x^{2} / \mathbf{d f}$ & P & GFI & CFI & NFI & RMSEA \\
\hline Full Model & 5.61 & 0.001 & 0.89 & 0.84 & 0.81 & 0.12 \\
Reduced Model & 2.57 & 0.001 & 0.97 & 0.94 & 0.91 & 0.07 \\
\hline
\end{tabular}

Note: GFI = goodness-of-fit index; CFI = comparative fit index; NFI = normed fit index; $x^{2} / \mathrm{df}=$ chi square/degrees of freedom; RMSEA = root mean square error of approximation; $\mathrm{P}=$ Probability.

Table 9

Sobel Test Statistics

\begin{tabular}{lcc}
\hline Mediational Paths & Test Statistics & SD \\
\hline Agreeableness-Opt.-SWB & $2.526^{* *}$ & 1.436 \\
Conscientiousness-Opt.-SWB & $2.679^{* *}$ & 1.419 \\
Neuroticism-Opt.-SWB & $3.805^{* *}$ & 1.397 \\
Positive Affect-Opt.-SWB & $6.255^{* *}$ & 0.711 \\
Object Resources-Opt.-SWB & $3.115^{* *}$ & 0.817 \\
Condition Resources-Opt.-SWB & $2.202^{* *}$ & 0.789 \\
\hline
\end{tabular}

Note: $S D=$ Standard Errors $; * p<.05, * * p<.01$

ever, the other two cognitive buffers (self-esteem and psychological control) did not mediate this relationship. According to Scheier and Carver (1985), "Optimists tend to adopt strategies that are more efficient when coping with stress" (as cited in Cook, 2003, p. 52). Scheier and Carver (1992) stated that optimism positively correlates with SWB and other positive psychological states of mind; whereas, this construct is negatively correlated with variables causing poor mental health or poor well-being such as neuroticism and anxiety. Positive affect and optimism also share a positive association (Marshall, Wortman, Kusulas, Hervig, \& Vickers Jr, 1992). Therefore, optimism is not merely a positive belief in one's future outcomes but a crucial mechanism of positive mental health and SWB homeostatic maintenance (Cook, 2003).

The present study results indicated that both internal and external resources are crucial for SWB homeostatic maintenance. It is noteworthy that not all indicators included in the SWB homeostasis theory and COR theory contribute equally to restoring and maintaining the level of SWB in recurrent flood survivors. However, testing of the integrated model provided insights into the dynamics of the SWB in identifying the crucial factors responsible for the maintenance of SWB.

Natural disasters can have long-standing psychosocial aftereffects on individuals and communities (Patel, Agrawal, \& Mathew, 2020). Different disaster-prone communities have framed their own cognitive references to cope with their challenging and stressful environment (Morrissey \& Reser, 2007). Despite its devastating aftereffects, there is a dearth of studies emphasizing the psychological theories and evidence-based applications to foster community preparedness and mental health (Morrissey \& Reser, 2007). The present study findings provide crucial insights in understanding the maintaining factors of SWB in the face of adversities. The findings can be utilized with individual therapies and help in planning the community disaster intervention policies. The current findings may help build the collective efficacy of a disaster-prone community by assessing the needs and building effective community intervention and preparedness programs.

\section{Applied Implications and Limitations}

This study provided crucial insights into the mechanisms of the internal and external factors maintaining the SWB of recurrent flood victims. These insights may have varied applied implications. Internal psychological buffers maintain SWB homeostasis within the normative range. However, external factors such as environmental stressors and external resources may influence these internal cognitive buffers (control, self-esteem, and optimism) and lead to either breakdown or maintenance of SWB. In the integrated model, among the internal buffers, 'optimism' turned out to be the most significant mediator in maintaining SWB. However, in the direct path model, perceived control also significantly predicted SWB along with optimism. These internal buffers may be addressed in psychological intervention programs (such as counseling, therapies) for the vulnerable population at risk of homeostatic breakdown. The SWB measure is an important indicator of homeostatic breakdown and risk of depression (Cook, 2003; Cummins, 2007). Furthermore, external resources, particularly object and condition resources were associated with internal buffers and SWB. These findings confirm that external resources, such as income and social support, could be crucial factors for SWB, particularly for the underprivileged population, such as victims of natural disasters. Interventions for these factors can be addressed at the individual and community level by various agencies such as government bodies and NGOs to prevent or decrease the distressing psychological aftereffects of these recurrent disasters and maintain the mental hygiene of the survivors. The present findings may provide important insights into the context of community-based interventions, including various psychotherapies, counseling camps, planning of disaster prevention, and 
mitigation policies.

As optimism was found to be a significant factor influencing SWB, it is noteworthy to mention that optimism can be a state or a trait (Kluemper, Little, \& DeGroot, 2009), and studies have shown that it can change over time if one's situation changes (Segerstrom, 2007). Many researchers have reported the positive impacts of various psychological interventions in optimism. Intervention strategies include best possible self-intervention (developing goals and visualizing best possible future self) (Meevissen, Peters, \& Alberts, 2011); selfcompassion training (Smeets, Neff, Alberts, \& Peters, 2014); cognitive-behavioral therapy methods or positive-psychology methods (e.g. Drozd, Mork, Nielsen, Raeder, \& Bjørkli, 2014). Furthermore, the experience of optimism may be influenced by culture. The support for this proposition indirectly comes from the research on optimistic bias. People with optimistic bias expect negative events as less likely to happen and positive events as more likely to happen when compared to an average person (Harris \& Hahn, 2011). Many studies have shown that optimistic bias is more robust among western countries with individualistic orientation than non-western interdependent cultures (Heine \& Hamamura, 2007). One possible reason could be a greater tendency for self-enhancement found in individualistic culture than collectivist cultures might manifest as optimistic bias (Joshi \& Carter, 2013). Therefore, therapists and counsellors should look into this interaction of person and culture and use appropriate strategies based on the need of the individuals.

This study was primarily aimed at understanding the dynamics of individual-level factors in maintaining SWB. However, the results of the study can be strengthened in terms of applications such as counselling and disaster mitigation programs by including community and cultural factors. Apparently, cultural aspects of native history and flood-related experiences and the values, beliefs, and social milieus are often found to exert profound influences upon the applicability of certain approaches (Thieken, Mariani, Longfield, \& Vanneuville, 2014). Almost every community has unique indigenous knowledge and coping styles to deal with flood hazards (Das, 2014; Thakuria, 2000). According to Das (2014), integrating the community perceptions of floods, local wisdom that has been passed through generations in oral traditions, and their indigenous coping techniques with the advanced technomanagerial approaches may benefit from mitigating the flood hazards more effectively. A proper acknowledgment and preservation of the community-specific traditional/indigenous coping strategies can significantly contribute to culture and region-specific relevant disaster mitigation programs (Fletcher et al., 2013). For example, the inhabitants of the Majuli Island (one of our study sites) perceive floods as an imperative phenomenon of their life and thus have adapted to certain structural and non-structural coping mechanisms at the individual and community level to deal with these recurrent fluvial disasters (Katyaini et al., 2012). Traditional coping strategies included building stilt houses approximately 7-15 feet above the ground level so that the floodwater cannot enter into their houses easily, locally made banana rafts, bamboo boats, county boats (small wooden boats) for transportation. Furthermore, studies have reported that community bonding and support, traditional and religious beliefs associated with the disasters or traumatic events may play a significant role in coping with the traumatic events (Hussain \& Bhushan, 2011). Therefore, rehabilitation programs and counselling sessions should address all these diverse individual, cultural, and community factors to increase their efficacy.

Although this study included participants from diverse socio-economic backgrounds, it is limited by sample size. Further, this study's results are based on data collected from the samples residing in one state of India (Assam), which might limit the generalization. This study may also have other limitations, such as confounding effects of many unaccounted variables that might have influenced the findings. Future research is needed to replicate the results of the present study. Future research can explore other possible factors such as resilience in the present model as it may also influence and maintain SWB homeostasis in the face of adversity. Furthermore, future studies should explore how specific cultural and traditional factors may influence the experience and coping strategies in response to recurrent floods and other natural disasters. In-depth qualitative research methods can also investigate detailed subjective views of the participants regarding such issues. The traditional and local coping strategies should be explored and addressed to address culturally relevant natural disaster mitigation policies and counseling.

\section{Funding}

This research received no external funding.

\section{Conflict of Interest}

The authors declare that they have no competing interests.

\section{References}

Ayers, T. (2011). Subjective wellbeing: An appraisal of the role of hpmood, approach-avoidant control, extraversion and neuroticism. (Bachelor's thesis: Deakin University, Australia). Retrieved from http://www - acqol . com.au/theses/index.php

Brende, J. O. (1998). Coping with floods: Assessment, intervention, and recovery processes for survivors and helpers. Journal of Contemporary Psychotherapy, 28(2), 107-139.

Burns, R. A., \& Machin, M. A. (2010). Identifying gender differences in the independent effects of personality and psychological well-being on two broad affect components of subjective well-being. Personality and Individual Differences, 48(1), 22-27.

Chen, Z., \& Davey, G. (2008). Happiness and subjective wellbeing in mainland China. Journal of Happiness Studies, 9(4), 589-600.

Cherry, K. E., Sampson, L., Galea, S., Marks, L. D., Nezat, P. F., Baudoin, K. H., \& Lyon, B. A. (2017). Opti- 
mism and hope after multiple disasters: Relationships to health-related quality of life. Journal of Loss and Trauma, 22(1), 61-76.

Cook, V. (2003). Subjective wellbeing: An integration of depression, stress, and homeostasis theory. (Doctoral dissertation, Deakin University, Australia). Retrieved from http://www. acqol.com . au/theses/index.php

Crawford, J. R., \& Henry, J. D. (2004). The Positive and Negative Affect Schedule (PANAS): Construct validity, measurement properties and normative data in a large non-clinical sample. British Journal of Clinical Psychology, 43(3), 245-265.

Cummins, R. A. (1995). On the trail of the gold standard for subjective well-being. Social Indicators Research, 35, 179-200.

Cummins, R. A. (1998). The second approximation to an international standard for life satisfaction. Social Indicators Research, 43(3), 307-334.

Cummins, R. A. (2000). Objective and subjective quality of life: An interactive model. Social Indicators Research, 52(1), 55-72.

Cummins, R. A. (2007, July). The distribution of resources, population happiness and public policy. Paper presented at PPDO 2007: International Conference on Happiness and Public Policy, Bangkok, Thailand.. Retrieved from http://www.happysociety.org/ ppdoconference/session_papers/ session13/session13_robert.pdf

Cummins, R. A. (2010). Subjective wellbeing, homeostatically protected mood and depression: A synthesis. Journal of Happiness Studies, 11(1), 1-17.

Cummins, R. A. (2012). The determinants of happiness. International Journal of Happiness and Development, l(1), 86-101.

Cummins, R. A. (2019). Issues of measurement and the interpretation of data. In K. D. Keith (Ed.), Wellbeing across cultures (pp. 516-530). Wiley Online Library.

Cummins, R. A., Gullone, E., \& Lau, A. L. (2002). A model of subjective well-being homeostasis: The role of personality. In E. Gullone \& R. A. Cummins (Eds.), The universality of subjective wellbeing indicators (pp. 7-46). Netherlands: Springer.

Cummins, R. A., \& Nistico, H. (2002). Maintaining life satisfaction: The role of positive cognitive bias. Journal of Happiness Studies, 3(1), 37-69.

Cummins, R. A., \& Wooden, M. (2014). Personal resilience in times of crisis: The implications of SWB homeostasis and set-points. Journal of Happiness Studies, 15(1), 223-235.

Das, D. (2014). 'Majuli in Peril': Challenging the received wisdom on flood control in Brahmaputra River Basin, Assam (1940-2000). Water History, 6(2), 167-185.

Davern, M. T., Cummins, R. A., \& Stokes, M. A. (2007). Subjective wellbeing as an affective-cognitive construct.
Journal of Happiness Studies, 8(4), 429-449.

Diener, E., \& Lucas, R. (1999). Personality, and subjective well-being. In D. Kahneman, E. Diener, \& N. Schwarz (Eds.), Well-being: The foundations of hedonic psychology (p. 213-229). New York: Russell Sage Foundation.

Doocy, S., Daniels, A., Murray, S., \& Kirsch, T. D. (2013). The human impact of floods: a historical review of events 1980-2009 and systematic literature review. PLOS Currents Distasters. Retrieved from http://currents.plos.org/ disasters/article/the-human-impact -of-floods-a-historical-review-of -events-1980-2009-and-systematic - literature-review/

Drozd, F., Mork, L., Nielsen, B., Raeder, S., \& Bjørkli, C. A. (2014). Better days-a randomized controlled trial of an internet-based positive psychology intervention. The Journal of Positive Psychology, 9(5), 377-388.

Fletcher, S. M., Thiessen, J., Gero, A., Rumsey, M., Kuruppu, N., \& Willetts, J. (2013). Traditional coping strategies and disaster response: Examples from the South Pacific Region. Journal of Environmental and Public Health, 1-9.

Franklin, C. (2013). Subjective wellbeing: The role of resilience and the resources maintaining the homeostatic system. (Unpublished Bachelor thesis. Deakin University, Victoria, Australia). Retrieved from http:// wWw . acqol . com. au/theses/index.php

Galinha, I. C., Garcia-Martin, M. Á., Oishi, S., Wirtz, D., \& Esteves, F. (2016). Cross-cultural comparison of personality traits, attachment security, and satisfaction with relationships as predictors of subjective well-being in India, Sweden, and the United States. Journal of Cross-Cultural Psychology, 47(8), 1033-1052.

Guha-Sapir, D., Hoyois, P., \& Below, R. (2013). Annual Disaster Statistical Review 2013 The Numbers and Trends. Brussels: CRED; 2014. Retrieved from http://www.cred.be/sites/ default/files/ADSR_2013.pdf

Gutiérrez, J. L. G., Jiménez, B. M., Hernández, E. G., Pcn, C., et al. (2005). Personality and subjective well-being: Big five correlates and demographic variables. Personality and Individual Differences, 38(7), 1561-1569.

Hall, B. J., Hobfoll, S. E., Palmieri, P. A., Canetti-Nisim, D., Shapira, O., Johnson, R. J., \& Galea, S. (2008). The psychological impact of impending forced settler disengagement in Gaza: Trauma and posttraumatic growth. Journal of Traumatic Stress, 21(1), 22-29.

Harris, A. J., \& Hahn, U. (2011). Unrealistic optimism about future life events: A cautionary note. Psychological Review, 118(1), 135-154.

Hayes, N., \& Joseph, S. (2003). Big 5 correlates of three measures of subjective well-being. Personality and Individual differences, 34(4), 723-727.

He, F., Cao, R., Feng, Z., Guan, H., \& Peng, J. (2013). The 
impacts of dispositional optimism and psychological resilience on the subjective well-being of burn patients: A structural equation modelling analysis. PloS one, 8(12), e82939.

Headey, B., \& Wearing, A. (1989). Personality, life events, and subjective well-being: Toward a dynamic equilibrium model. Journal of Personality and Social Psychology, 57(4), 731-739.

Heine, S. J., \& Hamamura, T. (2007). In search of East Asian self-enhancement. Personality and Social Psychology Review, 11(1), 4-27.

Henning, G., Hansson, I., Berg, A. I., Lindwall, M., \& Johansson, B. (2017). The role of personality for subjective well-being in the retirement transition-comparing variable-and person-oriented models. Personality and Individual Differences, 116, 385-392.

Hobfoll, S. E. (1988). The ecology of stress. Taylor \& Francis.

Hobfoll, S. E. (1989). Conservation of resources: A new attempt at conceptualizing stress. American Psychologist, 44(3), 513-524.

Hobfoll, S. E. (2001). The influence of culture, community, and the nested-self in the stress process: Advancing conservation of resources theory. Applied Psychology, 50(3), 337-421.

Hobfoll, S. E., \& Lilly, R. S. (1993). Resource conservation as a strategy for community psychology. Journal of Community Psychology, 21(2), 128-148.

Hobfoll, S. E., \& Stephens, M. A. P. (1990). Social support during extreme stress: Consequences and intervention. In B. R. Sarason (Ed.), Social support: An interactional view (p. 454-481). New York: Wiley.

Hofstede, G. (2001). Culture's consequences: Comparing values, behaviors, institutions and organizations across nations. Thousand Oaks, California: Sage Publications.

Hussain, D., \& Bhushan, B. (2011). Cultural factors promoting coping among Tibetan refugees: A qualitative investigation. Mental Health, Religion \& Culture, 14(6), 575-587.

Joshi, M. S., \& Carter, W. (2013). Unrealistic optimism: east and west? Frontiers in Psychology, 4(6). Retrieved from https: / /www. frontiersin.org/ articles/10.3389/fpsyg.2013.00006/ full

Kalayjian, A. S. (1995). Disaster and mass trauma: Global perspectives on post-disaster mental health management. Long Branch, NJ:Vista Publishing.

Kandilioti, G., \& Makropoulos, C. (2012). Preliminary flood risk assessment: the case of Athens. Natural Hazards, 61(2), 441-468.

Katyaini, S., Barua, A., \& Mili, B. (2012). Assessment of adaptations to floods through bottom up approach: A case of three agro climatic zones of Assam, India. The Clarion-International Multidisciplinary Journal, 1(1), 157-164.
Khine, M. S. (2013). Application of structural equation modeling in educational research and practice. Rotterdam: Sense Publishers.

Kline, R. B. (1998). Principles and practice of structural equation modeling. New York: Guilford Press.

Kluemper, D. H., Little, L. M., \& DeGroot, T. (2009). State or trait: Effects of state optimism on job-related outcomes. Journal of Organizational Behavior, 30(2), 209-231.

Kumar, K. J., \& Walia, A. (2013). India Disaster Report 2012. New Delhi: National Institute of Disaster Management (Ministry of home Affairs).

Lai, L. C., Cummins, R. A., \& Lau, A. L. (2013). Crosscultural difference in subjective wellbeing: Cultural response bias as an explanation. Social Indicators Research, 114(2), 607-619.

Lau, A. L., Cummins, R. A., \& Mcpherson, W. (2005). An investigation into the cross-cultural equivalence of the Personal Wellbeing Index. Social Indicators Research, 72(3), 403-430.

Lightfoot, E. S., Lesen, A. E., \& Ferreira, R. J. (2020). Gender and resilience in Gulf Coast communities: Risk and protective factors following a technological disaster. International Journal of Disaster Risk Reduction, 50, 101716

Lucas, R. (2008). Personality, and subjective well-being. In M. Eid \& R. J. Larsen (Eds.), The science of subjective well-being (p. 171-194). New York: Guilford Press.

Mahmood, K., \& Ghaffar, A. (2014). The relationship between resilience, psychological distress and subjective well-being among dengue fever survivors. Global Journal of Human-Social Science Research, 14(10), 13-20.

Marshall, G. N., Wortman, C. B., Kusulas, J. W., Hervig, L. K., \& Vickers Jr, R. R. (1992). Distinguishing optimism from pessimism: Relations to fundamental dimensions of mood and personality. Journal of Personality and Social Psychology, 62(6), 1067-1074.

Meevissen, Y. M., Peters, M. L., \& Alberts, H. J. (2011). Become more optimistic by imagining a best possible self: Effects of a two week intervention. Journal of Behavior Therapy and Experimental Psychiatry, 42(3), 371-378.

Merino, M. D., Privado, J., \& Arnaiz, R. (2019). Is there any relationship between unemployment in young graduates and psychological resources? An empirical research from the conservation of resources theory. Journal of Work and Organizational Psychology, 35(1), 1-8.

Morrison, P. S. (2019). Subjective and objective well-being. Scienze Regionali, 18(Speciale/2019), 651-656. doi: 10.14650/94671

Morrissey, S. A., \& Reser, J. P. (2007). Natural disasters, climate change and mental health considerations for rural Australia. Australian Journal of Rural Health, 15(2), 120-125.

Nunnally, J. (1967). Psychometric theory. New York, NY: McGraw-Hill. 
Nussbaum, M. (2000). Women's capabilities and social justice. Journal of Human Development, 1(2), 219247.

Patel, S. K., Agrawal, G., \& Mathew, B. (2020). Understanding the resilience and mental health impacts of natural disasters in India: A narrative review. International Journal of Population Studies, 6(1), 82-98.

Prati, G., \& Pietrantoni, L. (2009). Optimism, social support, and coping strategies as factors contributing to posttraumatic growth: A meta-analysis. Journal of Loss and Trauma, 14(5), 364-388.

Preacher, K., \& Leonardelli, G. (2003). Calculation for the sobel test: An interactive calculation tool for mediation tests. Retrieved from http://quantpsy.org/ sobel/sobel.htm

Rammstedt, B., \& John, O. P. (2007). Measuring personality in one minute or less: A 10-item short version of the Big Five Inventory in English and German. Journal of Research in Personality, 41(1), 203-212.

Rosenberg, M. (1965). Society and the adolescent self-image. Princeton, NJ: Princeton University Press.

Ryan, R. M., \& Deci, E. L. (2001). On happiness and human potentials: A review of research on hedonic and eudaimonic well-being. Annual Review of Psychology, 52(1), 141-166.

Sarma, D. (2013). Rural risk assessment due to flooding and riverbank erosion in Majuli, Assam, India. (Doctoral dissertation. University of Twente Indian Institute of Remote Sensing). Retrieved from https: / / www.itc.nl/library/ papers_2013/msc/gfm/sarma.pdf

Scheier, M. F., \& Carver, C. S. (1985). Optimism, coping, and health: assessment and implications of generalized outcome expectancies. Health Psychology, 4(3), 219247.

Scheier, M. F., \& Carver, C. S. (1992). Effects of optimism on psychological and physical well-being: Theoretical overview and empirical update. Cognitive Therapy and Research, 16(2), 201-228.

Scheier, M. F., Carver, C. S., \& Bridges, M. W. (1994). Distinguishing optimism from neuroticism (and trait anxiety, self-mastery, and self-esteem): A re-evaluation of the Life Orientation Test. Journal of Personality and Social Psychology, 67(6), 1063-1078.

Segerstrom, S. C. (2007). Optimism and resources: Effects on each other and on health over 10 years. Journal of Research in Personality, 41(4), 772-786.

Singh, P., Suar, D., \& Leiter, M. P. (2012). Antecedents, workrelated consequences, and buffers of job burnout among Indian software developers. Journal of Leadership \& Organizational Studies, 19(1), 83-104.

Smeets, E., Neff, K., Alberts, H., \& Peters, M. (2014). Meeting suffering with kindness: Effects of a brief selfcompassion intervention for female college students. Journal of Clinical Psychology, 70(9), 794-807.
Soto, C. J. (2015). Is happiness good for your personality? Concurrent and prospective relations of the big five with subjective well-being. Journal of Personality, 83(1), 45-55.

Suar, D., \& Gochhayat, J. (2016). Influence of biological sex and gender roles on ethicality. Journal of Business Ethics, 134(2), 199-208.

Thakuria, N. (2000). A geographical panorama of Majuli. Majuli Souvenir, 8-12.

Thieken, A. H., Mariani, S., Longfield, S., \& Vanneuville, W. (2014). Preface: Flood resilient communitiesmanaging the consequences of flooding. Natural Hazards and Earth System Sciences, 14(1), 33-39.

Tiliouine, H., Cummins, R. A., \& Davern, M. (2006). Measuring wellbeing in developing countries: The case of Algeria. Social Indicators Research, 75(1), 1-30.

Tomyn, A. J., \& Cummins, R. A. (2011). Subjective wellbeing and homeostatically protected mood: Theory validation with adolescents. Journal of Happiness Studies, 12(5), 897-914.

Tomyn, A. J., Mellor, D., Fuller-Tyszkiewicz, M., Cummins, R. A., \& Tanton, R. (2017). Geographic differences in subjective well-being among indigenous and nonindigenous Australian adolescents and adults. Journal of Community Psychology, 45(1), 81-99.

Veenhoven, R. (1994). Is happiness a trait?: Tests of the theory that a better society does not make people happier. Social Indicators Research, 33, 101-160.

Verger, P., Rotily, M., Hunault, C., Brenot, J., Baruffol, E., \& Bard, D. (2003). Assessment of exposure to a flood disaster in a mental-health study. Journal of Exposure Science \& Environmental Epidemiology, 13(6), 436442.

Vitters $\varnothing$, J. (2001). Personality traits and subjective wellbeing: Emotional stability, not extraversion, is probably the important predictor. Personality and Individual Differences, 31(6), 903-914.

Wahlstrom, M., \& Guha-Sapir, D. (2015). The Human Cost of Weather-Related Disasters 1995-2015. Geneva, Switzerland: UNISDR. Retrieved from http:// www. preventionweb. net/files/46796 _cop21weatherdisastersreport2015 .$p d f$

Watson, D., Clark, L. A., \& Tellegen, A. (1988). Development and validation of brief measures of positive and negative affect: the PANAS scales. Journal of Personality and Social Psychology, 54(6), 1063-1070. 